\title{
Sulphur K-edge XANES and acid volatile sulphide analyses of changes in chemical speciation of $S$ and Fe during sequential extraction of trace metals in anoxic sludge from biogas reactors
}

Sepehr Shakeri Yekta, Jenny Gustavsson, Bo H. Svensson and Ulf Skyllberg

\section{Linköping University Post Print}

N.B.: When citing this work, cite the original article.

Original Publication:

Sepehr Shakeri Yekta, Jenny Gustavsson, Bo H. Svensson and Ulf Skyllberg, Sulphur K-edge XANES and acid volatile sulphide analyses of changes in chemical speciation of $\mathrm{S}$ and $\mathrm{Fe}$ during sequential extraction of trace metals in anoxic sludge from biogas reactors, 2012, Talanta: The International Journal of Pure and Applied Analytical Chemistry, (89), 470-477. http://dx.doi.org/10.1016/j.talanta.2011.12.065

Copyright: Elsevier http://www.elsevier.com/

Postprint available at: Linköping University Electronic Press http://urn.kb.se/resolve?urn=urn:nbn:se:liu:diva-73112 


\title{
Sulfur K-edge XANES and acid volatile sulfide analyses of changes in chemical speciation of $S$ and Fe during sequential extraction of trace metals in anoxic sludge from biogas reactors.
}

\author{
Sepehr Shakeri Yekta ${ }^{a^{*}}$, Jenny Gustavsson ${ }^{a}$, Bo H. Svensson ${ }^{a}$, Ulf Skyllberg ${ }^{b}$ \\ ${ }^{\mathrm{a}}$ Department of Thematic Studies -Water and Environment, Linköping University, SE-581 83 \\ Linköping, Sweden
}

${ }^{\mathrm{b}}$ Department of Forest Ecology and Management, Swedish University of Agricultural Sciences, SE-901 83 Umeå, Sweden
*Corresponding author at Department of Thematic Studies-Water and Environment, Linköping University, SE-581 83 Linköping, Sweden. Tel.:+46 13282294; Fax: +46 13133630.

E-mail addresses: sepehr.shakeri.yekta@liu.se, jenny.gustavsson@liu.se, bo.svensson@liu.se, ulf.skyllberg@slu.se

\begin{abstract}
The effect of sequential extraction of trace metals on sulfur (S) speciation in anoxic sludge samples from two lab-scale biogas reactors augmented with Fe was investigated. Analyses of sulfur K-edge X-ray absorption near edge structure (S XANES) spectroscopy and acid volatile sulfide (AVS) were conducted on the residues from each step of the sequential extraction. The $\mathrm{S}$ speciation in sludge samples after AVS analysis was also determined by $\mathrm{S}$ XANES. Sulfur was mainly present as FeS ( $\sim 60 \%$ of total $S)$ and reduced organic S $(\sim 30 \%$ of total S), such as organic sulfide and thiol groups, in the anoxic solid phase. Sulfur XANES and AVS analyses showed that during first step of the extraction procedure (the removal of exchangeable cations), a part of the FeS fraction corresponding to $20 \%$ of total $\mathrm{S}$ was transformed to zero-valent $\mathrm{S}$, whereas Fe was not released into the solution during this transformation. After the last extraction step (organic/sulfide fraction) a secondary Fe phase was formed. The change in chemical speciation of $\mathrm{S}$ and Fe occurring during sequential extraction procedure suggests indirect effects on trace metals associated to the FeS fraction
\end{abstract}


that may lead to incorrect results. Furthermore, by S XANES it was verified that the AVS analysis effectively removed the FeS fraction. The present results identified critical limitations for the application of sequential extraction for trace metal speciation analysis outside the framework for which the methods were developed.

Keywords: Sequential extraction, Biogas, Sulfur speciation, Sulfur K-edge XANES, Acid volatile sulfide, Trace metals.

\section{Introduction}

Sequential extraction methods are widely used for characterization of chemical forms or fractions of metals in samples from soil, sediment, and sludge. Reagents, such as solutions of neutral salts, weak and strong acids as well as reducing and oxidizing compounds, are selected to be as specific as possible towards solubilization of metal binding fractions. Thus, it is assumed that the reagents extract specific forms of metals in a mixture of metal species[1, 2]. The reagents are applied in a successive manner with increasing degree of reactivity. Accordingly, metals released after the extraction steps are attributed to operationally defined fractions ranging from loosely bound to strongly bound forms [1-4]. Attribution of the specified fractions to certain chemical forms or phases of metals has uncertainties associated with selectivity of the reagents and additive effects caused by reactions occurring in a mixture of metal forms and sequentially added reagents [5].

Trace metals are important micronutrients for growth and activity of microorganisms in biogas reactors in which organic content of the influent material is biologically converted to methane and carbon dioxide under anaerobic conditions [6-10]. Processes regulating the chemical speciation and bioavailability of trace metals are complex involving dynamic interaction of microorganisms with organic and inorganic compounds [11, 12]. Laboratory and practical evidences have demonstrated that speciation and bioavailability of trace metals essential for the anaerobic digestion process are highly influenced by the chemistry of sulfur (S) [11-15]. The precipitation of metal sulfide phases and/or adsorption of trace metals to iron sulfide particles are considered to be the most important processes contributing to trace metal dynamics in biogas reactors. The sequential extraction methods are widely used for analysis of trace metal fractionations in sludge from biogas reactors e.g. [16-19], but possible changes in the S chemistry during sequential extractions, and how they may affect operationally 
defined trace metal fractions, have not been investigated previously for sludge samples from biogas reactors. In a parallel study, we observed that Co (but not Ni) was encountered in the residual fraction (after extraction of organic/sulfide bonded trace metals) of a biogas sludge together with Fe (Gustavsson et al., unpublished). The question arose whether or not this was due to an artifactual formation of an Fe-phase during the extraction procedure, to which $\mathrm{Co}$ was associated.

The objective of the present study was to determine the chemical speciation of $\mathrm{S}$ in sludge form biogas reactors, and to investigate possible changes in the chemical speciation of $\mathrm{S}$ and Fe during a sequential extraction procedure used for trace metal speciation. The feasibility of three different sequential extraction procedures used for analysis of trace metal fractionations in anaerobic granular sludge were compared by Hullebusch et al. [17]. They suggested that a modified version of the method developed by Tessier et al. [1] as described by Osuna et al. [4], has a better reproducibility and reagent selectivity compared to other sequential extraction methods. We used sulfur K-edge X-ray absorption near edge structure (S XANES) spectroscopy and acid volatile sulfide (AVS) extraction as analytical tools to quantify changes in $\mathrm{S}$ speciation during sequential extraction scheme of the modified Tessier method [1,4].

Sulfur K-edge XANES is a suitable method for identification and quantification of various $\mathrm{S}$ compounds, their oxidation states and binding forms in a sample [20,21], which allow us to follow the fate of S species during sequential extraction. Acid volatile sulfide analysis is a classical approach for measurement of the sulfide fraction reactive towards metals in anoxic samples, based on volatilization of reduced $\mathrm{S}$ bonded in mineral fractions, mainly FeS [12, 22, 23]. The method has in principal similar disadvantages as sequential extraction regarding the uncertainty in selectivity of the applied reagent for volatilization of reduced $\mathrm{S}$ compounds and simultaneously extracted metals [22]. To analyze possible changes in S forms during AVS extraction, we used S XANES to compare the S speciation before and after AVS analysis. To our knowledge, this is the first study quantifying changes in the S chemistry using S XANES, during sequential extraction of metals and before and after AVS extraction. Thus, this study will contribute to a better understanding of the accuracy of sequential extraction of trace metals, as well as AVS analysis, in general and their indirect effects on trace metal speciation in sludge samples from biogas reactors in particular. 


\section{Material and methods}

\subsection{Sample sources}

Samples were taken from two lab-scale biogas reactors semi-continuously fed with grain stillage. The reactors, designated as $\mathrm{J} 2$ and $\mathrm{J} 4$, were operated at $37^{\circ} \mathrm{C}$ with a hydraulic retention time (HRT) of 20 days and organic loading rates (OLR) of 2.5 and $4.0 \mathrm{~g} \mathrm{~L}^{-1} \mathrm{~d}^{-1}$ volatile solid (VS), respectively. The only difference between J2 and J4 is their different

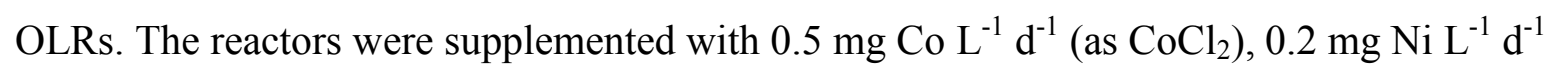
(as $\mathrm{NiCl}_{2}$ ) and $0.5 \mathrm{~g} \mathrm{Fe} \mathrm{L}^{-1} \mathrm{~d}^{-1}$ (as a solution with $\mathrm{Fe}(\mathrm{III})$ : Fe(II) ratio of 2:1). Trace metals were added in order to provide the microbial community with micronutrients. Iron was supplemented to precipitate inorganic sulfide and decrease the $\mathrm{H}_{2} \mathrm{~S}$ concentration in biogas. For a detailed description of the operational conditions and rationale for trace metal and $\mathrm{Fe}$ addition, the reader is referred to Gustavsson et al. [10].

\subsection{Sequential extraction}

Bulk sludge samples were transported to an anaerobic box (Vinyl Anaerobic Airlock Chamber type Coy, Coy Laboratories Inc., US) containing gas composition of $\mathrm{CO}_{2}(40 \%)$, $\mathrm{N}_{2}(55 \%)$, and $\mathrm{H}_{2}(5 \%)$. The $\mathrm{CO}_{2}$ was introduced into the chamber in order to simulate the headspace of biogas reactor and avoid degassing of dissolved $\mathrm{CO}_{2}$ from sludge liquid when exposed to box atmosphere, which otherwise may result in a $\mathrm{pH}$ change of the sludge. $\mathrm{The}_{2}$ was used in order to remove traces of oxygen in contact with located palladium catalyst in the anaerobic box. Sub-samples were transferred into polypropylene tubes (Falcon, Sarstedt, Germany) and centrifuged at $10000 \mathrm{rpm}$ for $10 \mathrm{~min}$. The supernatant was decanted and its $\mathrm{Fe}$ concentration was measured by atomic absorption spectroscopy (AAS, 1100 Atomic Absorption Spectrophotometer, Perkin Elmer, US). Sub-samples corresponding to a dry mass of 0.18 to $0.30 \mathrm{~g}$ were used for sequential extraction of modified Tessier following the protocol by Osuna et al. [4].Total solid (TS) content of the samples was measured according to Swedish Standard method (SS-028113) by drying the samples at $105^{\circ} \mathrm{C}$ for $20 \mathrm{~h}$.

A summary of the sequential extraction procedure is given in Table 1, beginning with a centrifugation of sludge and analysis of metals in the sludge liquid fraction. Results on trace metals such as Ni and Co will be reported in Gustavsson et al. [unpublished]. Here we only report Fe (as determined by AAS) after each sequential extraction step. The solid residue after each step was washed with deaerated Milli-Q water, centrifuged and the Fe concentration in 
the supernatant was measured in order to check possible Fe release from the solid phase during the washing step. After decanting the water, the reagent for extraction of the next fraction was added to the tubes. The same procedure was applied for all extraction steps. The two first fractions (i.e. exchangeable and carbonate) were extracted inside the anaerobic box to avoid exposure of the samples to air and oxidation of reduced S species. The residual fraction, i.e. last step of the sequential extraction, was extracted according to Swedish Standard method (SS-028311) for extraction of metals from sludge by 7M nitric acid in an autoclave (at $120^{\circ} \mathrm{C}$ for $30 \mathrm{~min}$ ). The total $\mathrm{S}$ content of the samples was analyzed by Eurofins Environment Sweden AB (Lidköping, Sweden).

Table 1. Summary of modified Tessier procedure for the sequential extraction of trace metals $[1,4]$.

\begin{tabular}{|c|c|c|c|}
\hline Extraction step & Reagent & $\begin{array}{l}\text { Volume of } \\
\text { reagent } \\
(\mathrm{ml})\end{array}$ & Conditions \\
\hline Sludge liquid phase & - & - & $\begin{array}{l}\text { Centrifugation, } 10000 \mathrm{rpm} \\
10 \mathrm{~min} \text {, inside the anaerobic } \\
\text { box }\end{array}$ \\
\hline Exchangeable fraction & $\begin{array}{l}1 \mathrm{M} \text { ammonium } \\
\text { acetate }\end{array}$ & 10 & $\begin{array}{l}\mathrm{pH} 7, \text { shaken for } 1 \mathrm{~h}, 150 \\
\mathrm{rpm}, 20^{\circ} \mathrm{C} \text {, inside the } \\
\text { anaerobic box }\end{array}$ \\
\hline Carbonate fraction & $1 \mathrm{M}$ sodium acetate & 10 & $\begin{array}{l}\mathrm{pH} 5.5 \text {, shaken for } 1 \mathrm{~h}, 150 \\
\mathrm{rpm}, 20^{\circ} \mathrm{C} \text {, inside the } \\
\text { anaerobic box }\end{array}$ \\
\hline $\begin{array}{l}\text { Organic/sulfide } \\
\text { fraction }\end{array}$ & $\begin{array}{l}30 \% \text { hydrogen } \\
\text { peroxide }\end{array}$ & 5 & $\begin{array}{l}\mathrm{pH} 2 \text { (adjusted by nitric } \\
\text { acid), shaken for } 3 \mathrm{~h}, 150 \\
\mathrm{rpm}, 37^{\circ} \mathrm{C}\end{array}$ \\
\hline Residual fraction & 7M nitric acid & 20 & $\begin{array}{l}\text { Autoclaved for } 30 \mathrm{~min} \text {, } \\
120^{\circ} \mathrm{C}\end{array}$ \\
\hline
\end{tabular}

\subsection{Acid volatile sulfide (AVS)}

The AVS method presented by Hsieh and Yang [24] and modified by Brouwer and Murphy [25] and Leonard et al. [26] was applied in the present study. The AVS extraction was performed in the anaerobic box to avoid oxidation of sulfide due to exposure to air. In summary, 0.18 to $0.30 \mathrm{~g}$ TS of sludge was transferred into a $250 \mathrm{ml}$ glass bottle with a vial attached to its inner wall. The vial was filled up with $10 \mathrm{~mL}$ of sulfide antioxidant buffer (SAOB) solution containing $2 \mathrm{M} \mathrm{NaOH}, 0.1 \mathrm{M}$ ascorbic acid and $0.1 \mathrm{M}$ EDTA. $25 \mathrm{ml}$ of $1 \mathrm{M}$ $\mathrm{HCl}$ acid was added to the glass bottles. The bottles were caped and the solid suspension was stirred by a magnetic stirrer for $1 \mathrm{~h}$. The addition of $\mathrm{HCl}$ results in volatilization of reduced, 
inorganic S compounds of the solid phase which is trapped by the SAOB solution in the vial attached to the inner wall of the reaction bottle. After $1 \mathrm{~h}$, the liquid fraction was centrifuged and its Fe concentration was measured using AAS. The concentration of sulfide in SAOB solution (AVS) was measured using a sulfide sensor (Ag/S 800 Wissenschaftlich-Technische Werkstätten, Germany). The sensor was calibrated with $0.1 \mathrm{M} \mathrm{Na} 2 \mathrm{~S} \cdot 9 \mathrm{H}_{2} \mathrm{O}$ diluted in SAOB solution to sulfide concentrations ranging from $10^{-5}$ to $10^{-2} \mathrm{M}$, which covered all the measured AVS concentrations. For more information about the details of AVS experimental setup the reader is referred to Brouwer and Murphy [25] and Leonard et al. [26].

\subsection{Quality control of extraction procedures}

The extraction reagents were prepared using Milli-Q water purged with $\mathrm{N}_{2}$ to degas dissolved oxygen. All the chemicals were of analytical reagent grade. Glassware was washed with acid (7M nitric acid for sequential extraction and 10\% hydrochloric acid for AVS analysis) for $48 \mathrm{~h}$ and rinsed with Milli-Q water at least three times. The tubes and glass bottles were stored in the anaerobic chamber two days before analysis to ensure strict anaerobic conditions. Sequential extraction and AVS was performed on triplicate samples. Furthermore, sulfide was spiked in Milli-Q water purged with $\mathrm{N}_{2}$ and AVS analysis was performed in order to check the recovery of the analysis as well as the possible oxidizing effect of remaining traces of dissolved oxygen in reagents on AVS. Spiked and blank samples were analyzed to detect possible matrix interferences and contamination sources. The sulfide sensor was calibrated after every six measurements in order to correct for drift of the sensor signal.

\subsection{Sulfur K-edge XANES data collection and analysis}

The S XANES analysis was performed at the semi-conductive wiggler beamline I811 at MAX-lab, Lund University, Sweden. The monochromator consists of crystal pairs of Si(111) with a wavelength resolution of $0.25 \mathrm{eV}$ at the $\mathrm{S}$ K-edge energy $(2472 \mathrm{eV})$. Sludge samples were dried in an anaerobic box filled with Ar. After grinding with mortar and pestle, the dried sample powder was pressed on S-free tape to form a thin film in order to minimize selfabsorption effects [27]. Samples were covered with S-free plastic foil to avoid exposure to air during transport from the anaerobic box to the sample chamber, which was continuously purged with He gas. The S XANES spectra were recorded in fluorescence mode using a PIPS detector at room temperature. Samples were typically scanned by incident X-ray energy over the range of 2450 to $2500 \mathrm{eV}$ using a quick scan mode. Average spectra consist of 3 to 10 individual scans. From each averaged spectrum a polynomial pre-edge function was 
subtracted and data were normalized between 2460 and $2490 \mathrm{eV}$ using software WinXAS97 [28]. The energy was reported relative to elemental $\mathrm{S}(2472.7 \mathrm{eV})$, setting the maximum of the $\mathrm{Na}_{2} \mathrm{~S}_{2} \mathrm{O}_{3}$ first peak at $2472.0 \mathrm{eV}$ [29].

Microsoft Excel was used to deconvolute the S XANES spectrum for each sample into pseudo-components by a least-square fitting procedure. We used a modified version of the method reported by Xia et al. [20]. In short, $\mathrm{s} \rightarrow \mathrm{p}$ transitions of $\mathrm{S}$ atoms in $\mathrm{FeS}, \mathrm{FeS}_{2}$, elemental S, cysteine (RSH), methionine (RSR), cystine (RSSR), sulfonate and sulfate, occurring between 2470 and 2480 eV, were modelled by Gaussian peaks. Peak energy maxima and standard deviations for the Gaussian curves of the model compounds are reported as supplementary data (Table S1). One Gaussian peak was used to fit the sum of RSH and RSR due to the proximity of their energy maxima which are within the beam energy resolution of $0.25 \mathrm{eV}$. Two Gaussian peaks were used to fit the double cysteine (RSSR) peak. The increase in background caused by the transition of ejected photoelectrons to the continuum was modelled by arctangent step functions located at $0.8 \mathrm{eV}$ above each peak maximum of $\mathrm{FeS}, \mathrm{FeS}_{2}$, elemental $\mathrm{S}$, the sum of RSH and RSR, sulfonate and sulfate. The post-absorption-edge pattern of the reduced S species, FeS, $\mathrm{FeS}_{2}$, elemental S, RSH, RSR and RSSR, occurring in the energy range of 4.0 to $8.0 \mathrm{eV}$ relative to elemental $\mathrm{S}$, was modelled using two Gaussian peaks, one representing the sum of RSH and RSR and one representing the sum of $\mathrm{FeS}, \mathrm{FeS}_{2}$, elemental S and RSSR. The absolute concentrations of the $\mathrm{S}$ components were calculated by multiplying the relative $\mathrm{S}$ composition with the total $\mathrm{S}$ concentration of the sample, after correction of the absorption cross-section for the oxidation state [20]. Because of peak broadening caused by self-absorption effects and the proximity of $\mathrm{FeS}_{2}$ and elemental S peaks, the sum of these two compounds and possible polysulfides are reported as zero-valent $\mathrm{S}$.

\subsection{Experimental protocol}

Figure 1 shows the scheme of the experimental procedure used in S XANES and AVS analyses. The bulk sludge samples taken from biogas reactors (J2 and J4) were divided into 20 tubes. The samples were centrifuged and the liquid fraction was decanted. Three tubes were selected for AVS analysis and one was kept sealed and stored at $-80^{\circ} \mathrm{C}$ for the S XANES analysis. The residue remaining after AVS extraction was immediately frozen and stored at $80^{\circ} \mathrm{C}$ for S XANES analysis. After each step of the sequential extraction procedure the residue in three tubes was selected for AVS analysis, and one tube was immediately frozen at 
$-80^{\circ} \mathrm{C}$ for S XANES analysis. The variation in AVS concentration determined in the three replicate tubes after each step of sequential extraction was evaluated by student t-test. Due to coherent structure of the residues from organic/sulfide fraction, it was not possible to grind them with the mortar and the pestle in order to provide homogeneous powder for the $S$ XANES analysis and therefore, their S XANES spectra were not recorded.

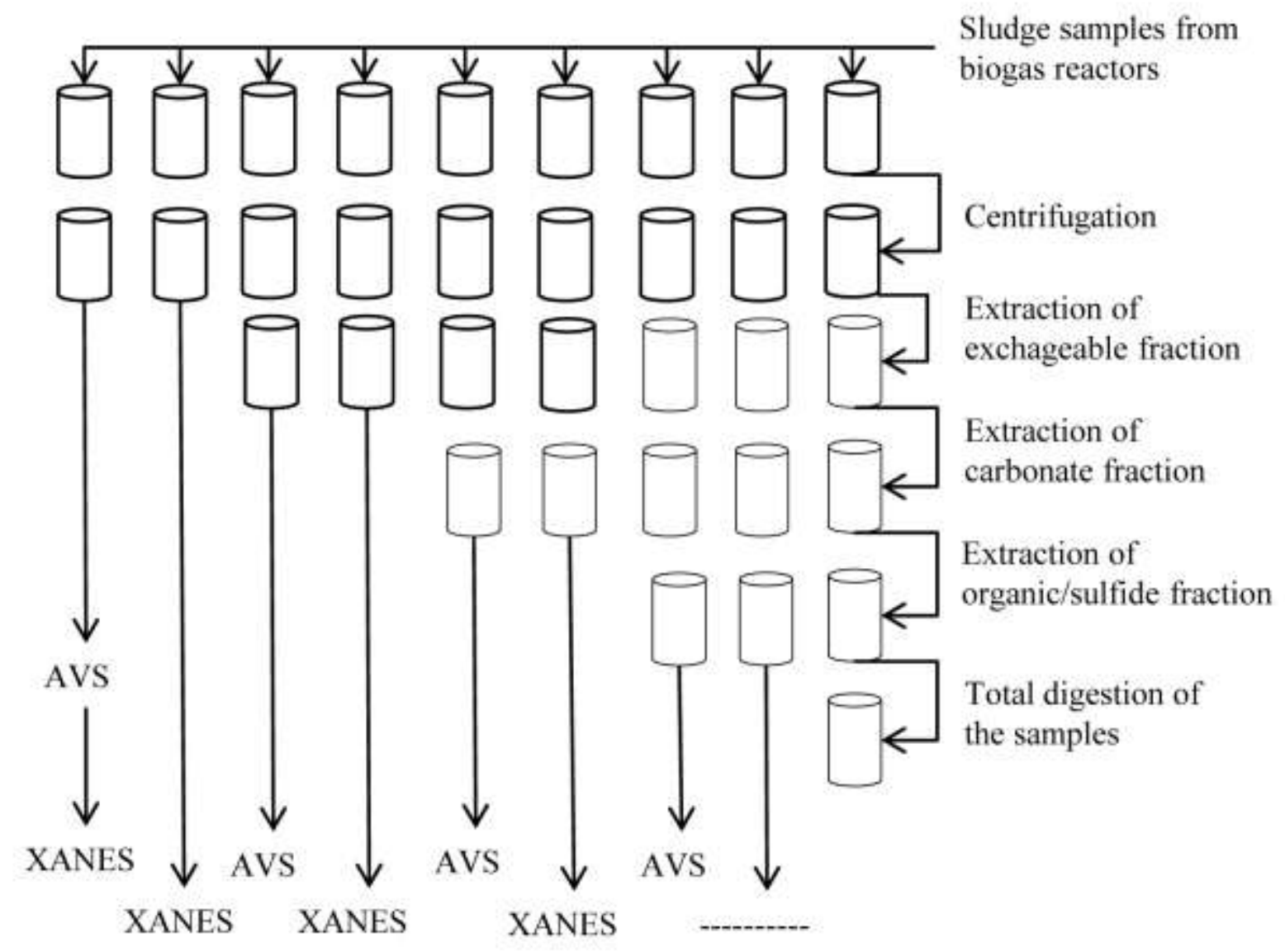

Fig. 1. Experimental protocol applied for S XANES and AVS analyses on sludge samples from $\mathrm{J} 2$ and $\mathrm{J} 4$ biogas reactors and on solid residues from each step of the sequential extraction. The arrows show the flow of sludge samples through the experimental procedure.

\section{Results and discussion}

\subsection{Sulfur K-edge XANES}

\subsubsection{Sulfur speciation in the solid phase of the original sludge}

Linear least-square fits of S XANES spectra from the sludge solid phases of the biogas reactors, as well as solid residues after each step of sequential extraction and AVS analysis 
are shown in Fig. 2 (reactor J2) and Fig. S1 (reactor J4). The spectra were quite similar for both reactors, and are composed of several maxima in the XANES region, representing multiple oxidation states of $\mathrm{S}$. The peak with a maximum at approximately $-2.6 \mathrm{eV}$ relative to elemental $\mathrm{S}$ is $\mathrm{FeS}$, and the peak occurring at approximately $1 \mathrm{eV}$ relative to elemental $\mathrm{S}$ represents reduced organic S (i.e. the sum of organic sulfides, organic disulfides and thiols). Two groups of oxidized S representing sulfonate and sulfate with peak energies at 8.3 and 10 $\mathrm{eV}$ relative to elemental S, respectively, are also observed. Sulfonate is an organic compound, and sulfate likely is represented by sulfate esters (carbon-bonded sulfate). The peak at approximately $4.5 \mathrm{eV}$ is the post-edge background caused by the sum of reduced $\mathrm{S}$ species.

Seven Gaussian distribution functions were used to model the S XANES spectra of the solid fraction of sludge from J2 and J4 reactors. Energies for peak maxima and standard deviations of the model compound Gaussian curves are reported as supplementary data (Table S1). The percentage contribution from each model compound to total S content of the sludge solid phase of $\mathrm{J} 2$ and $\mathrm{J} 4$ are reported in (Table 2). Iron sulfide (FeS) accounted for $62 \%$ and $63 \%$ of total $\mathrm{S}$ in $\mathrm{J} 2$ and $\mathrm{J} 4$, respectively. The grain stillage used as reactor feed, was provided from downstream of bioethanol production plant in which sulfuric acid is applied for $\mathrm{pH}$ adjustment during the process. Therefore, the feed material of the studied biogas reactors is initially rich in inorganic oxidized S. During the anaerobic digestion process, the oxidized S of the feed material is reduced, resulting in production of mainly sulfide [30]. The laboratory reactors were supplemented with $\mathrm{Fe}$ (as a solution with a $\mathrm{Fe}(\mathrm{III}): \mathrm{Fe}(\mathrm{II})$ ratio of $2: 1$ at a rate of $\left.0.5 \mathrm{~g} \mathrm{Fe} \mathrm{L}^{-1} \mathrm{~d}^{-1}\right)$ in order to decrease the $\mathrm{H}_{2} \mathrm{~S}(\mathrm{~g})$ concentration in the biogas. Added Fe(III) is reduced (chemically or by iron reducing-bacteria), and $\mathrm{FeS}(\mathrm{s})$ is precipitated. 


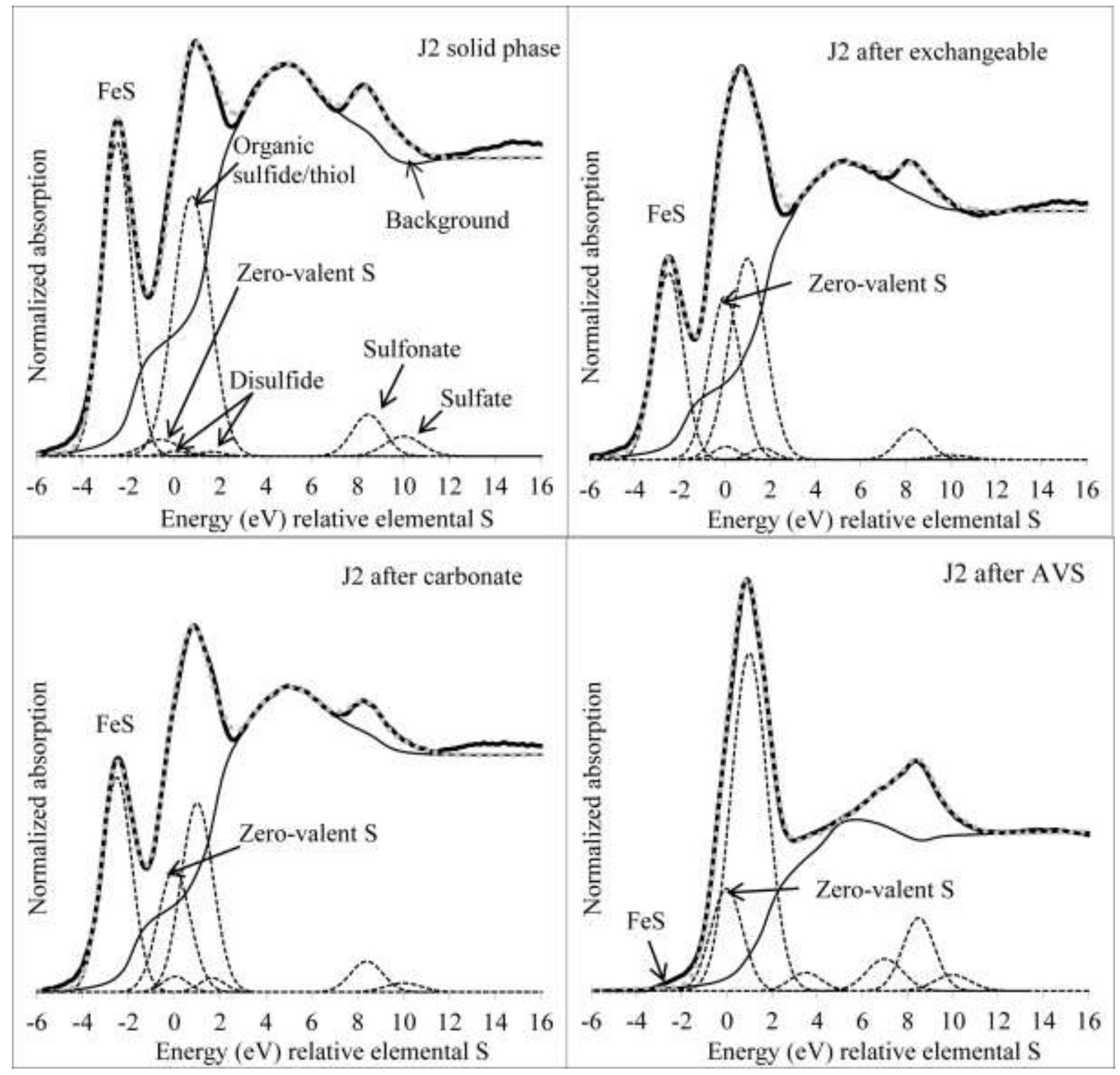

Fig.2. Normalized S XANES spectra of the original solid sludge from the $\mathrm{J} 2$ reactor and solid residues after each step of sequential and AVS extraction (thick, solid line). Gaussian distribution functions, each representing a model compound, are shown by dashed lines.

Overall model fits are represented by the grey dotted line and the thin, solid line represents the background. 
Table 2. Distribution of different $\mathrm{S}$ forms (\% of total $\mathrm{S}$ ) in the sludge solid phase of $\mathrm{J} 2$ and $\mathrm{J} 4$ and in solid residues after sequential extraction steps and AVS on untreated sludge samples, as determined by $\mathrm{S}$ XANES. Sulfate was likely dominated by sulfate esters. Zero-valent $\mathrm{S}$ may include some pyrite $\left(\mathrm{FeS}_{2}\right)$. n.d. means not-detected. Merit-of-fit represents percentage of the data which cannot be explained by the model.

\begin{tabular}{lllllllll}
\hline & $\begin{array}{l}\text { J2 solid } \\
\text { phase }\end{array}$ & $\begin{array}{l}\text { J2 after } \\
\text { exchangeable }\end{array}$ & $\begin{array}{l}\text { J2 after } \\
\text { carbonate }\end{array}$ & $\begin{array}{l}\text { J2 after } \\
\text { AVS }\end{array}$ & $\begin{array}{l}\text { J4 solid } \\
\text { phase }\end{array}$ & $\begin{array}{l}\text { J4 after } \\
\text { exchangeable }\end{array}$ & $\begin{array}{l}\text { J4 after } \\
\text { carbonate }\end{array}$ & $\begin{array}{l}\text { J4 after } \\
\text { AVS }\end{array}$ \\
\hline FeS & 61.7 & 43.4 & 52 & n.d. & 63 & 45.5 & 41.4 & 6.7 \\
Zero-valent S & 2.6 & 23.8 & 18.4 & 20 & 4.4 & 23.8 & 25.7 & 24.4 \\
Organic & 31.9 & 28.2 & 24 & 66.8 & 28.7 & 22.3 & 28.1 & 55.8 \\
sulfide/thiol & & & & & & & & \\
Disulfide & $<1.0$ & 2.5 & 3.1 & n.d. & 2.8 & 7.5 & 3.6 & n.d. \\
Sulfoxide & n.d. & n.d. & n.d. & 2.4 & n.d. & n.d. & n.d. & 3.8 \\
Sulfone & n.d. & n.d. & n.d. & 3.4 & n.d. & n.d. & n.d. & 2.7 \\
Sulfonate & 2 & 1.8 & 1.9 & 6.1 & $<1.0$ & $<1.0$ & 1.2 & 5 \\
Sulfate & $<1.0$ & $<1.0$ & $<1.0$ & 1.3 & $<1.0$ & n.d. & n.d. & 1.6 \\
aMerit-of-fit & 4.3 & 3.9 & 4.4 & 4.5 & 8.9 & 4.2 & 3.5 & 3.0 \\
\hline
\end{tabular}

a) Merit-of-fit $=100 \times\left[\Sigma\left(\right.\right.$ Normalized $_{\text {absorption }}$ measured - Normalized absorption $\left.\left._{\text {fit }}\right)^{2}\right] / \Sigma\left(\text { Normalized absorption }_{\text {measured }}\right)^{2}$

The sum of organic sulfide and thiol was $32 \%$ and $29 \%$ of total S in the solid fraction of sludge of J2 and J4, respectively. Sulfur-containing amino acids and peptides are major compounds contributing to these S forms. Part of the organic sulfide/thiol may be the result of sulfurization processes occurring at high sulfide concentrations, when reactive sites of degraded organic particles are "quenched" by inorganic sulfide under the formation of thiol functional groups [31,32]. Thiol groups in turn react to form mono- and disulfidic (-S- and S-S-) bridges in organic compounds [33]. Despite daily supplementation of Fe to the reactors, the concentration of $\mathrm{Fe}$ in the liquid fraction was below the detection limit (precipitated as $\mathrm{FeS})$. In contrast, inorganic sulfide was available in the liquid phase, as well as in the gaseous phase with concentrations of $\mathrm{H}_{2} \mathrm{~S}(\mathrm{~g})$ reaching 0.3 and $0.4 \%$ in the headspace of $\mathrm{J} 2$ and $\mathrm{J} 4$ reactors, respectively. Therefore, sulfide was in excess and could take part in the sulfurization of labile organic compounds. It is noteworthy that the S XANES results also reflect the presence of biologically inherited S-containing organic compounds. Due to the small difference in absorption energy and possible peak broadening caused by self-absorption 
effects, it is not possible to distinguish between the contribution from small concentrations of pyritic $\mathrm{S}\left(\mathrm{FeS}_{2}\right)$, elemental $\mathrm{S}$ and polysulfides. The fitting of a single Gaussian peak as representative for the zero-valent $\mathrm{S}$ demonstrated that approximately $2.6 \%$ and $4.4 \%$ of total $\mathrm{S}$ was present as pyrite, elemental S, polysulfides or a mixture of these compounds in J2 and J4, respectively. The overall contribution of organic, oxidized S (mainly sulfonate and estersulfate) was approximately $3 \%$ in $\mathrm{J} 2$ and $2 \%$ in $\mathrm{J} 4$.

\subsubsection{Changes in sulfur speciation during sequential extraction}

The recorded spectra for the sludge solid phase, and solid residues after extraction of exchangeable and carbonate fractions are stacked in Fig. 3 for comparative purposes and data of the model fits are reported as absolute concentrations (mg S gTS $\left.{ }^{-1}\right)$ in Fig.4. For these calculations, it was assumed that the total $\mathrm{S}$ concentration of solid residue after the exchangeable and carbonate extraction steps remained unchanged within errors of measurements as compared to the total $\mathrm{S}$ concentration in the original solid phase of the sludge (16 mg S gTS ${ }^{-1}$ for $\mathrm{J}_{2}$ and $13 \mathrm{mg} \mathrm{S} \mathrm{gTS}^{-1}$ for J4). The S XANES results show that during the first step of the sequential extraction (i.e. for the exchangeable fraction) approximately $20 \%$ of total $\mathrm{S}$ is transformed to zero-valent $\mathrm{S}$ in samples from both reactors (increase in zero-valent S concentrations from 0.4 to $3.8\left(\mathrm{mg} \mathrm{S} \mathrm{gTS}^{-1}\right)$ for J2 and from 0.6 to 3.1 ( $\mathrm{mg} \mathrm{S} \mathrm{gTS}^{-1}$ ) for J4, Fig. 4). The increase in zero-valent $\mathrm{S}$ roughly corresponds to the decrease in FeS. Thus, considering a relative error of about $\pm 5-10 \%$ in the quantification of the different $\mathrm{S}$-forms by $\mathrm{S}$ XANES, it is concluded that the major change taking place during the extraction of the exchangeable fraction is an oxidation of FeS to zero-valent $\mathrm{S}$ (likely elemental or polysulfidic S). Pyrite is slowly formed by partial oxidation of FeS in natural environments such as sediments [34], but it is highly unlikely that the short time used in the sequential extraction procedure would be enough for formation of pyrite.

Because Fe was not detected in the solution, neither after the exchangeable nor after the carbonate extraction step, the transformation of FeS to zero-valent $\mathrm{S}$ did not result in a mobilization of $\mathrm{Fe}$ from the solid phase. Thus, Fe released upon the oxidation of FeS can be assumed to have reacted with the remaining sludge solid matrix e.g. organic compounds [35]. The change in speciation of Fe caused by the exchangeable extraction step, will directly affect the results of $\mathrm{Fe}$ fractionation, and indirectly the fractionation of other trace metals during the following sequential extraction steps. In both $\mathrm{J} 2$ and $\mathrm{J} 4$ samples, the concentration of reduced 
organic $\mathrm{S}$ forms decreased slightly after extraction of the exchangeable fraction. Interestingly, the changes in the concentration of FeS, elemental S and organic forms of S caused by the exchangeable extraction step, remained largely unaffected during the subsequent carbonate extraction step (Fig. 4).

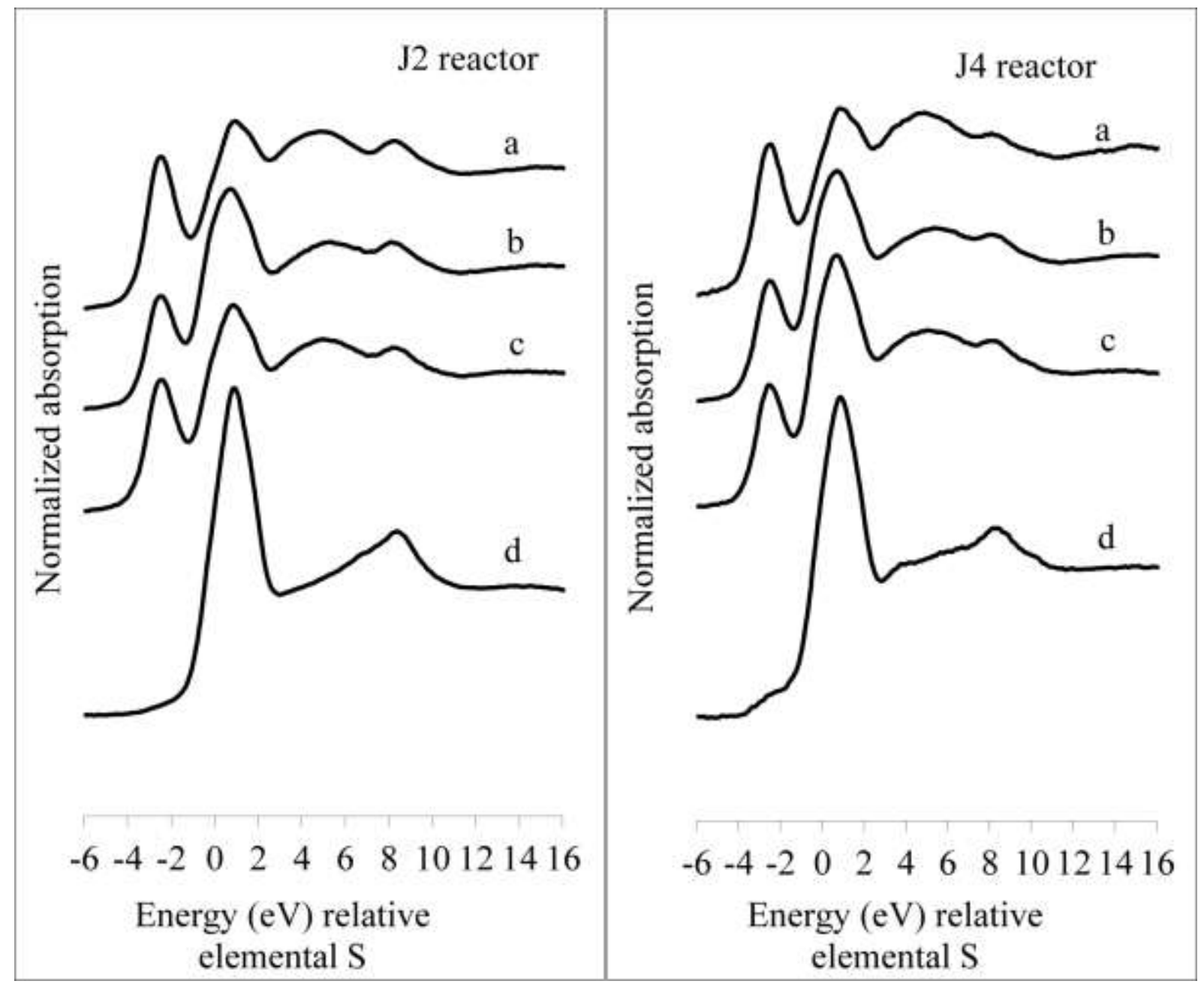

Fig. 3. Comparison of normalized S XANES spectra for the $\mathrm{J} 2$ and $\mathrm{J} 4$ reactors of the solid sludge (a), solid residue after the extraction of exchangeable fraction (b), carbonate fraction (c), and AVS (d). For clarity the spectra are shifted along the y-axis (arbitrary units). 


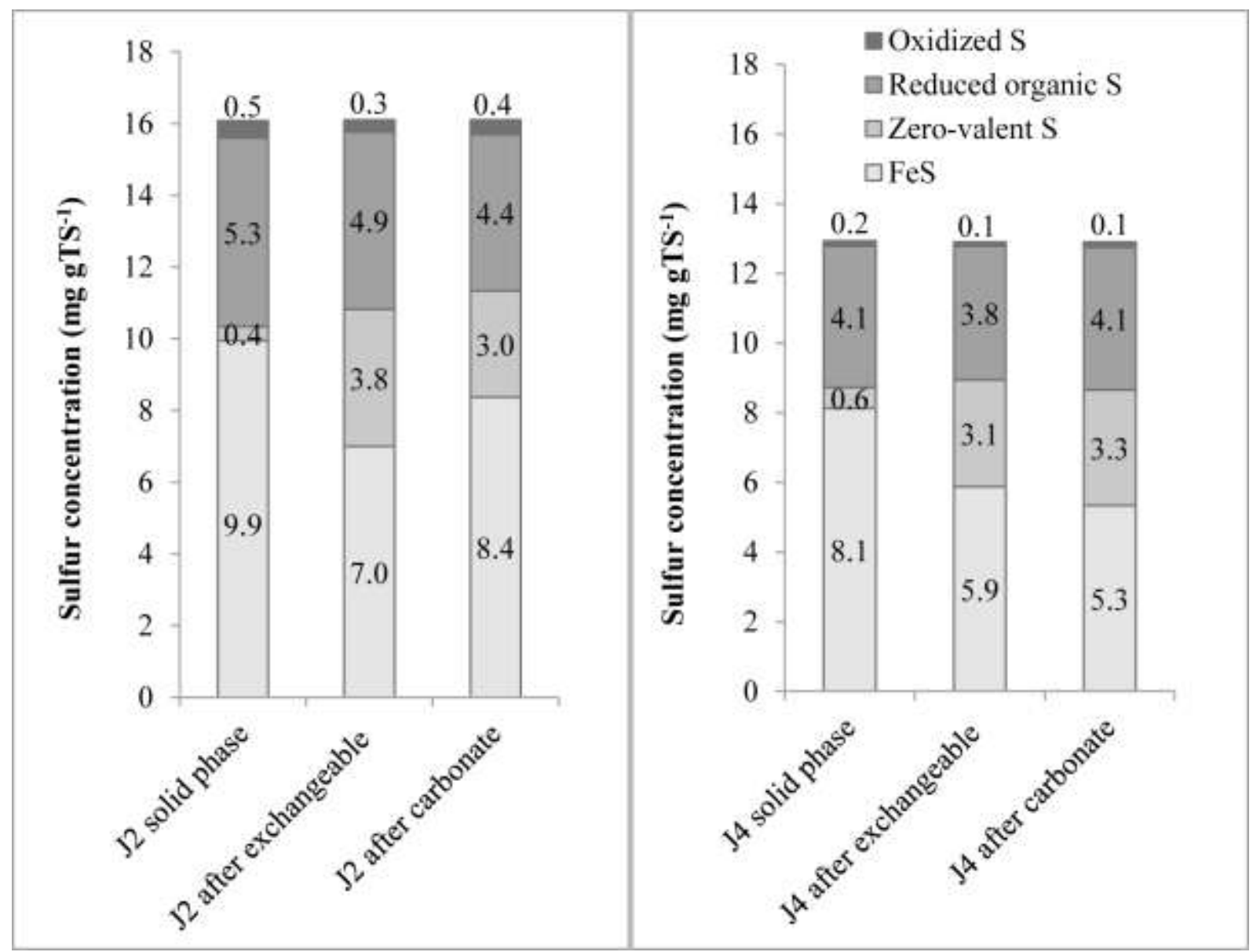

Fig. 4. Concentration of major sulfur forms in the original sludge from the $\mathrm{J} 2$ and $\mathrm{J} 4$ biogas reactors, as well as in the residues after exchangeable and carbonate extraction steps as determined by $\mathrm{S}$ XANES.

\subsubsection{Changes in sulfur speciation after $A V S$}

The relative concentrations of S components in the solid phase of the sludge and in the residue after AVS extraction are compared in Table 2, and the absolute concentrations in Table 3. The total S concentration in residues after the AVS extractions was calculated by subtracting the measured AVS from the total S concentration in J2 and J4. During the AVS extraction, addition of $1 \mathrm{M} \mathrm{HCl}$ to the sludge samples volatilized reduced inorganic $\mathrm{S}$. No FeS remained in J2 samples after AVS extraction, as shown by removal of the first peak (at approximately $-2.6 \mathrm{eV}$ relative elemental $\mathrm{S}$ representing $\mathrm{FeS}$ ) in the S XANES spectrum (Fig.3). However, in the $\mathrm{J} 4$ sample a small shoulder remained at $-2.6 \mathrm{eV}$ relative elemental $\mathrm{S}$, corresponding to $0.3 \mathrm{mg} \mathrm{S} g T S^{-1}$, suggesting that the added $\mathrm{HCl}$ was not enough to reach a complete volatilization of FeS in this sample (Fig. 3). It is also noted in Table 3 that the AVS extraction step resulted in a partial transformation of S to zero-valent S (an increase from 0.4 


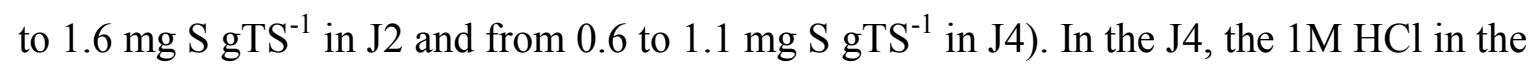
AVS extraction seems to have attacked some thiols or organic sulfides (decrease from 3.7 to $2.5 \mathrm{mg} \mathrm{S} \mathrm{gTS}^{-1}$ ). Small increases in sulfoxide and sulfonate is insignificant, and within the error of the method used to deconvolute the S XANES spectrum.

Table 3. Absolute concentrations of $\mathrm{S}$ components $\left(\mathrm{mg} \mathrm{S} \mathrm{g} \mathrm{TS}^{-1}\right)$ in the sludge solid phase of samples from the $\mathrm{J} 2$ and $\mathrm{J} 4$ biogas reactors, and in residues after AVS extraction as determined by S XANES.

\begin{tabular}{lllll}
\hline & $\begin{array}{l}\text { J2 solid } \\
\text { phase }\end{array}$ & $\begin{array}{l}\text { J2 after } \\
\text { AVS }\end{array}$ & $\begin{array}{l}\text { J4 solid } \\
\text { phase }\end{array}$ & $\begin{array}{l}\text { J4 after } \\
\text { AVS }\end{array}$ \\
\hline FeS & 9.9 & - & 8.1 & 0.3 \\
Zero-valent S & 0.4 & 1.6 & 0.6 & 1.1 \\
Organic & 5.1 & 5.3 & 3.7 & 2.5 \\
sulfide/thiol & & - & 0.4 & - \\
Disulfide & 0.2 & 0.2 & - & 0.2 \\
Sulfoxide & - & 0.3 & - & 0.1 \\
Sulfone & - & 0.5 & 0.1 & 0.2 \\
Sulfonate & 0.3 & 0.1 & 0.1 & 0.1 \\
Sulfate & 0.2 & & & \\
\hline
\end{tabular}

In the $\mathrm{J} 4$ sample, the concentration of FeS determined by S XANES $\left(8.1 \mathrm{mg} \mathrm{S} \mathrm{gTS}^{-1}\right)$ was well in agreement with the AVS determinations $\left(8.4 \mathrm{mg} \mathrm{S}\right.$ gTS $\left.^{-1}\right)$ in the original sludge. However, for the $\mathrm{J} 2$ sample there was a discrepancy between $\mathrm{FeS}$, as determined by $\mathrm{S}$ XANES (9.9 $\mathrm{mg} \mathrm{S} \mathrm{gTS}^{-1}$ ) and AVS (7.9 $\left.\mathrm{mg} \mathrm{S} \mathrm{gTS}^{-1}\right)$. The reason for this is unclear. The FeS fraction as determined by $\mathrm{S}$ XANES comprises a consortium of possible iron monosulfides with slightly different ordering (microcrystallinity) and stoichiometry. Mackinawite (microcrystalline $\mathrm{FeS})$, pyrrhotite $\left(\mathrm{Fe}_{1-\mathrm{x}} \mathrm{S}\right)$ and greigite $\left(\mathrm{Fe}_{3} \mathrm{~S}_{4}\right.$, an intermediate in the formation of pyrite from mackinawite) are possible phases, which may occur in the sludge. While these forms may be included in the model peak for FeS in the XANES spectrum, AVS analysis is not equally efficient as an extractant of these FeS minerals. Rickard and Morse [22] demonstrated that the extraction efficiency of $1 \mathrm{M} \mathrm{HCl}$ for synthetic mackinawite, and synthetic greigite was $92 \%$ and $40-67 \%$, respectively.

\subsection{Changes in AVS and simultaneously extracted Fe during sequential extraction}


Despite some differences in absolute concentrations, the relative changes in $\mathrm{S}$ speciation observed after the exchangeable extraction step by S XANES (Fig. 4) were also noted in the AVS analysis of both J2 and J4 samples (Table 4). Results of t-tests on the measured AVS for every step of sequential extraction showed that the AVS fraction decreased significantly $(p<0.05)$ after the exchangeable step during the extraction of exchangeable fraction. Thus, the AVS analysis also confirmed that during the extraction of the exchangeable fraction some of the iron monosulfides were oxidized (to elemental S or other forms of zero-valent S), and were not volatilized as AVS. No statistically significant change in the AVS concentration did occur during the carbonate extraction. Because no Fe was released into solution during oxidation of $\mathrm{FeS}$ to zero-valent $\mathrm{S}$ in the exchangeable step, it is suggested that Fe was adsorbed to the sludge matrix and/or a secondary phase of Fe was formed. In contrast to AVS, the concentration of simultaneously extracted Fe (AVS-Fe) did not change after neither the extraction steps of the exchangeable or carbonate fractions (Table 4). Thus, the AVS-Fe extraction by $1 \mathrm{M} \mathrm{HCl}$ was powerful enough to release not only $\mathrm{FeS}$, but also secondary phases of Fe formed during this step (as well as all other extraction steps).

Table 4. Acid volatile sulfide (AVS) and simultaneously extracted Fe (AVS-Fe) concentrations $\left(\mathrm{mg} \mathrm{g} \mathrm{TS}^{-1}\right)$ in residues after each sequential extraction step (mean \pm standard deviation, $\mathrm{n}=3$ )

\begin{tabular}{lllll}
\hline & J2-AVS- Fe & J4-AVS-Fe & J2-AVS & J4-AVS \\
\hline Sludge solid phase & $11 \pm 0.2$ & $12 \pm 0.4$ & $7.9 \pm 0.0$ & $8.4 \pm 0.7$ \\
After exchangeable & $11 \pm 0.1$ & $12 \pm 0.4$ & $6.8 \pm 0.3$ & $7.2 \pm 0.0$ \\
After carbonate & $11 \pm 0.3$ & $11 \pm 0.1$ & $7.0 \pm 0.3$ & $6.7 \pm 0.3$ \\
After organic/sulfide & $2.6 \pm 1.3$ & $3.2 \pm 0.7$ & $0.0 \pm 0.0$ & $0.0 \pm 0.0$ \\
\hline
\end{tabular}

After the extraction of the organic/sulfide fraction by $30 \%$ hydrogen peroxide at $\mathrm{pH} 2.0$, no AVS was detected, which was expected due to oxidation of sulfides by the hydrogen peroxide. However, still 2.6 and $3.2 \mathrm{mg} \mathrm{Fe} \mathrm{gTS}^{-1}$ was released in the AVS extraction from the solid residues of $\mathrm{J} 2$ and $\mathrm{J} 4$, respectively (Table 4). This suggests a formation of a secondary Fe phase during extraction of organic/sulfide fraction by the hydrogen peroxide at low $\mathrm{pH}$. Considering the low pH (2.0) and high concentrations of sulfate (by oxidiation of sulfide), jarosite $(\mathrm{H}, \mathrm{K}, \mathrm{Na}) \mathrm{Fe}_{3}(\mathrm{OH})_{6}(\mathrm{SO} 4)_{2}(\mathrm{~s})$ is a much possible secondary precipitate, but also 
schwertmannite $\mathrm{Fe}_{8} \mathrm{O}_{8}(\mathrm{OH})_{6} \mathrm{SO}_{4}(\mathrm{~s})$ may form if $\mathrm{pH}$ is raised above 2.5 during reaction between the extraction solution and the sludge [36].

\subsection{Possible Fe-involving reactions during the extraction step of the exchangeable fraction}

The results of the S XANES analysis (Fig. 4) and the AVS (Table 4) extractions revealed a partial oxidation of iron monosulfides to zero-valent $\mathrm{S}$ during the sequential extraction of the exchangeable fraction. Two main mechanisms have been proposed for oxidation of metal sulfides depending on the structure of the sulfide minerals and environmental conditions [37]. Disulfide minerals such as pyrite are oxidized via the "thiosulfate mechanism" by attack of an oxidizing agent resulting in a sequence of reactions with production of sulfate as the end product. Acid soluble sulfide minerals such as FeS are oxidized through a "polysulfide mechanism" by attack of an oxidizing agent and protons on the metal sulfide lattice. This results in an oxidation of $\mathrm{FeS}$ to polysulfide as an intermediate compound and further formation of elemental S [37, 38].

A prerequisite for oxidation of $\mathrm{FeS}$ is the availability of potential electron acceptors. In environmental samples, major electron acceptors thermodynamically capable of oxidizing FeS are $\mathrm{O}_{2}, \mathrm{NO}_{3}{ }^{-}, \mathrm{Mn}(\mathrm{IV})$ oxides, and $\mathrm{Fe}(\mathrm{III})$ oxides [39]. In this study, proper measures were undertaken to avoid exposure of the samples to $\mathrm{O}_{2}$ during the extraction procedures by flushing the reagents water with $\mathrm{N}_{2}$ and performing extraction procedures (i.e. centrifugation, decanting of supernatant, and shaking, see Table 1) in an anaerobic box. Thus, it is unlikely that the transformation of FeS during extraction of the exchangeable fraction was due to an oxidation by $\mathrm{O}_{2}$. Furthermore, if the $\mathrm{S}$ oxidation was due to a contamination of samples with $\mathrm{O}_{2}$ during the extraction procedure, the solid residue after carbonate extraction should also be more oxidized compared to the previous step.

Manganese (IV) has been proposed to be an oxidation agent for FeS to zero-valent S [39]. However, the low concentration of Mn in the samples (data not shown) makes such a transition unlikely. Fe(III) ions are known to act as oxidizing agents for metal sulfides at circumneutral and acidic conditions [37] and Fe(III) is assumed to be the main oxidizing agent responsible for $\mathrm{FeS}$ oxidation in the absence of $\mathrm{MnO}_{2}$ [39]. It has also been demonstrated that Fe(III) ions are more efficient oxidizers of metal sulfides than oxygen [40, 
41]. Sand et al. [37] proposed the following reaction scheme for oxidation of metal sulfides (MeS) via a "polysulfide mechanism" in the presence of Fe(III):

$\mathrm{MeS}+\mathrm{Fe}^{3+}+\mathrm{H}^{+} \rightarrow \mathrm{Me}^{2+}+0.5 \mathrm{H}_{2} \mathrm{~S}_{\mathrm{n}}+\mathrm{Fe}^{2+}(\mathrm{n} \geq 2)$

$0.5 \mathrm{H}_{2} \mathrm{~S}_{\mathrm{n}}+\mathrm{Fe}^{3+} \rightarrow 0.125 \mathrm{~S}_{8}+\mathrm{Fe}^{2+}+\mathrm{H}^{+}$

Rapin et al [40] applied a sequential extraction method, which included the extraction of a "Fe and Mn oxide fraction" for sediment samples and performed AVS analysis for every step. They showed that, under anaerobic condition, AVS was preserved during exchangeable and carbonate extraction, but it was reduced by $5 \%$ after "Fe and Mn oxide" extraction. The same observations were reported by Ngima and Lim [41] by measurements of the redox potential after each step in a sequential extraction scheme. It was suggested that released Fe(III) ions concurrent with reduction of Fe oxides during sequential extraction acted as the oxidizing agent for FeS oxidation.

The presence of oxide minerals in sludge samples is unlikely, due to overall anoxic conditions in biogas reactors. However, daily supplementation of $0.5 \mathrm{~g} \mathrm{Fe} \mathrm{L}^{-1} \mathrm{~d}^{-1}$ using a solution with $\mathrm{Fe}(\mathrm{III}): \mathrm{Fe}(\mathrm{II})$ ratio of 2:1 might be a source of short term Fe(III) accumulation in the system. In general, $\mathrm{Fe}(\mathrm{III})$ is reduced to $\mathrm{Fe}(\mathrm{II})$ chemically and/or biologically by iron-reducing bacteria, during the anaerobic digestion process [42]. The rate of $\mathrm{Fe}(\mathrm{III})$ reduction might be limited by the availability of Fe(III) through processes like; complexation of Fe(III) with organic and/or inorganic compounds, particle aggregation, Fe(III)-cell membrane contact, as well as a passivation of cells and mineral active sites by other available ions [43]. Thus, it is possible that the daily addition of Fe(III) to the sludge may have resulted in a short-term build-up of less available Fe(III) forms in the solid phase of the reactors. The extraction step with 1.0 $\mathrm{M}$ ammonium acetate (Table 1), as well as addition of $1 \mathrm{M} \mathrm{HCl}$ during the AVS extraction, might dissolve Fe(III) from the sludge matrix, which in turn may act as a FeSoxidizing agent and promote oxidation of FeS to elemental $\mathrm{S}$ during the extraction procedures. According to (eq.1) and (eq.2) the end products of these reactions are Fe(II) and elemental S. The Fe(II) formed upon oxidation may have been incorporated as organic and inorganic complexes or precipitates $(\mathrm{FeS})$ in the sludge solid matrix.

\section{Conclusions}


In this study we have used S XANES spectroscopy and AVS extraction to 1) determine the chemical speciation of sulfur, and 2) evaluate a method used to sequentially extract trace metals in anoxic sludge from two lab-scale biogas reactors fed with grain stillage and augmented with $\mathrm{Fe}(\mathrm{II}, \mathrm{III})$. The results demonstrated that $\mathrm{S}$ is mainly present as FeS (62 and $63 \%$ in $\mathrm{J} 2$ and $\mathrm{J} 4$, respectively) and reduced, organic S (32 and $29 \%$ in $\mathrm{J} 2$ and $\mathrm{J} 4$, respectively) in the anoxic solid phase of the sludge samples. A small fraction of the $\mathrm{S}$ was identified as zero-valent $S$ (or possibly pyrite) in the original sludge. The first step of the sequential extraction procedure (the exchangeable fraction) resulted in partial oxidation of the FeS fraction to zero-valent S. Iron was not dissolved upon this FeS oxidation implying a transformation of Fe from a sulfide mineral to another fraction or secondary formed phase in the solid matrix. These results were confirmed qualitatively by the AVS analysis.

Furthermore, during the organic/sulfide extraction step (by $30 \% \mathrm{H}_{2} \mathrm{O}_{2}$ at $\mathrm{pH} 2.0$ ), 24-27\% of Fe remained unextracted but it was dissolved by the AVS extraction step, despite the fact that the AVS concentration was zero. This suggests that the organic/sulfide extraction step dissolved FeS, but a secondary Fe phase (likely jarosite) was formed. The change in Fe and $\mathrm{S}$ speciation during sequential extraction might lead to inaccurate results for the speciation of trace metals like e.g. Co and Ni, known to associate to FeS by co-precipitation and/or adsorption. Results from a parallel study on trace metal speciation in sludge samples from J2 and $\mathrm{J} 4$ by Gustavsson et al. [unpublished] demonstrated that Co was associated with Fe in the residual fraction of the sludge samples, whereas $\mathrm{Ni}$ was $100 \%$ associated with the organic/sulfide fraction. The finding of the present study which showed a secondary phase of Fe was formed after extraction of organic/sulfide fraction may suggest that Co remaining in the residual fraction likely was caused by an association to this Fe phase, possibly jarosite. It is known that $\mathrm{Co}$ and $\mathrm{Ni}$ can be incorporated by a substitution for $\mathrm{Fe}(\mathrm{III})$ in the jarosite structure $[44,45]$. Accordingly, the results from the present study revealed critical limitations for the application of sequential extraction of trace metal speciation analysis outside the framework for which the methods were developed particularly for samples from biogas reactors augmented with $\mathrm{Fe}(\mathrm{II})$ and $\mathrm{F}$ (III) for removal of sulfide from biogas product.

\section{Acknowledgements}

This study was funded by The Swedish Energy Agency. The authors would like to thank Lena Lundman and the staff of the MAX-lab in Lund, Katarina Norén and Stefan Carlson, for help 
with laboratory experiments. Anna Karlsson and Jörgen Ejlertsson are acknowledged for help with designing the lab-scale reactors. We thank David Bastviken and two anonymous reviewers of the article for their constructive comments. We also thank Lantmännen Agroetanol AB, Norrköping, Sweden, for providing grain stillage.

\section{References}

[1] A. Tessier, P.G.C. Campbell, M. Blsson, Anal. Chem. 51 (1979) 844-851.

[2] A.V. Filgueiras, I. Lavilla, C. Bendicho, J. Environ. Monitor. 4 (2002) 823-857.

[3] R.C. Stover, L.E. Sommers, D.J. Silviera, J. Water Pollut. Con. F. 48 (1976) 2165-2175.

[4] M. B. Osuna, E.D. van Hullebusch, M.H. Zandvoort, J. Iza, P.N.L. Lens, J. Environ. Qual. 33 (2004) 1256-1270.

[5]M. Kersten, U. Forstner, Water Sci. Technol. 18 (1986) 121-130.

[6]A. Espinosa, L. Rosas, K. Ilangovan, A. Noyola, Water Sci. Technol. 32 (1995) 121-129.

[7] J.E. Burgess, J. Quarmby, T. Stephenson, Process Saf. Environ. Prot. 77 (1999) 199-204.

[8]S.F. Aquino, D.C. Stuckey, J. Environ. Eng. 133 (2007) 28-35.

[9] X.M. Feng, A. Karlsson, B.H. Svensson, S. Bertilsson, FEMS Microbiol. Ecol. 74 (2010) 226-240.

[10] J. Gustavsson, B.H. Svensson, A. Karlsson, Water Sci. Technol. 64 (2011) 320-325.

[11] S. Jansen, G. Gonzalez-Gil, H.P. van Leeuwen, Enzyme Microb.Technol. 40 (2007) 823830.

[12] A. Van der Veen, F.G. Fermoso, P.N.L. Lens, Eng. Life Sci. 7 (2007) 480-489.

[13] I.J. Callander, J.P. Barford, Biotechnol. Lett. 5 (1983) 755-760.

[14] G. Gonzalez-Gil, R. Kleerebezem, G. Lettinga, Appl. Environ. Microbiol. 65 (1999) 1789-1793. 
[15]F.G. Fermoso, J. Bartacek, S. Jansen, P.N.L. Lens, Sci. Total Environ. 407 (2009) 36523667.

[16] I.R. Leighton, C.F. Forster, Bioresource. Technol. 63 (1998) 131-137.

[17] E.D.V. Hullebusch, S. Utomo, M.H. Zandvoort, P.N. L. Lens, Talanta. 65 (2005) 549558.

[18] Q.-H. Hu, X.-F. Li, G.-C. Du, J. Chen, Chem. Eng. J. 143 (2008) 111-116.

[19] C.E. Marcato, E. Pinelli, M. Cecchi, P. Winterton, M. Guiresse, Ecotox. Environ. Safe. 72 (2009) 1538-1544.

[20] K. Xia, F. Weesner, W.F. Bleam, P.R. Bloom, U.L. Skyllberg, P.A. Helmke, Soil Sci. Soc. Am. J. 62 (1998) 1240-1246.

[21] F. Jalilehvand, Chem. Soc. Rev. 35 (2006) 1256-1268.

[22] D. Rickard, J.W. Morse, Mar. Chem. 97 (2005) 141-197.

[23] T. Jong, D.L. Parry J. Environ. Monitor. 6 (2004) 278-285.

[24] Y.P. Hsieh, C.H. Yang, Limnol. Oceanogr. 34 (1989) 1126-1130.

[25] H. Brouwer, T.P. Murphy, Environ. Toxicol. Chem. 13 (1994) 1273-1275.

[26] E.N. Leonard, A.M. Cotter, G.T. Ankley, Environ. Toxicol. Chem. 15 (1996) 1479-1481.

[27] G.S. Waldo, R.M. Fronko, J.E. Penner-Hahn, Biochemistry (N. Y.). 30 (1991) 1048610490 .

[28] T. Ressler, J. Synchrotron Rad. 5 (1998) 118-122.

[29] M.A. Williamson, J.D. Rimstidt, Geochim.Cosmochim.Acta. 58 (1994) 5443-5454.

[30] E. Colleran, S. Finnegan, P. Lens, Anton. Leeuw. Int. J. G.67 (1995) 29-46.

[31] A. Vairavamurthy, K. Mopper, Nature. 329 (1987) 623-625.

[32] T.I. Eglinton, J.E. Irvine, A. Vairavamurthy, W. Zhou, B. Manowitz, Org. Geochem. 22 (1994) 781-799. 
[33] J.S. SinningheDamste, J.W. De Leeuw, Org.Geochem. 16 (1990) 1077-1101.

[34] R.T. Wilkin, H.L. Barnes, Geochim. Cosmochim.Acta. 60 (1996) 4167-4179.

[35] J.M. Santana-Casiano, M. González-Dávila, M.J. Rodríguez, F.J. Millero, Mar. Chem. 70 (2000) 211-222.

[36] J.M. Bigham, U. Schwertmann, S.J. Traina, R.L. Winland, M. Wolf, Geochim. Cosmochim.Acta. 60 (1996) 2111-2121.

[37] W. Sand, T. Gehrke, P.-.Jozsa, A. Schippers, Hydrometallurgy. 59 (2001) 159-175.

[38] A. Schippers, H. Von Rège, W. Sand, Minerals Eng. 9 (1996) 1069-1079.

[39] A. Schippers, B.B. Jorgensen, Geochim. Cosmochim.Acta. 65 (2001) 915-922.

[40] F. Rapin, A. Tessler, P.G.C. Campbell, R. Carignan, Environ. Sci. Technol. 20 (1986) 836-840.

[41] L.-S. Ngiam, P.-E. Lim, Sci. Total Environ. 275 (2001) 53-61.

[42] P.H. Nielsen, B. Frølund, S. Spring, F. Caccavo Jr., Syst. Appl.Microbiol. 20 (1997) 645651 .

[43] M. Pédrot, A.L. Boudec, M. Davranche, A. Dia, O. Henin, J. Colloid Interf. Sci. 359 (2011) 75-85.

[44] J.E. Dutrizac, T.T. Chen, Can. Metall. Q. 43 (2004) 305-320.

[45] C. Yang, W. Qin, S. Lai, J. Wang, Y. Zhang, F. Jiao, L. Ren, T. Zhuang, Z. Chang, Hydrometallurgy. 106 (2011) 32-37. 


\section{Supplementary data}

Sulphur K-edge XANES and acid volatile sulphide analyses of changes in chemical speciation of sulphur during sequential extraction of trace metals in anoxic sludge from biogas reactors.

Sepehr Shakeri Yekta $^{\mathrm{a}^{*}}$, Jenny Gustavsson ${ }^{\mathrm{a}}$, Bo H. Svensson ${ }^{\mathrm{a}}$, Ulf Skyllberg ${ }^{\mathrm{b}}$

${ }^{\mathrm{a}}$ Department of Thematic Studies -Water and Environment, LinköpingUniversity, SE-58183

Linköping, Sweden

${ }^{\mathrm{b}}$ Department of Forest Ecology and Management, Swedish University of Agricultural Sciences, SE-901 83 Umeå, Sweden

*Corresponding author at Department of Thematic Studies -Water and Environment, LinköpingUniversity, SE-58183 Linköping, Sweden. Tel.:+46 13282294; Fax: +46 13133630.

\section{Content}

Fig. S1. Normalized S XANES spectra of sludge solid phase and solid residues after each step of sequential extraction and AVS from J4 reactor.

Table S1. Peak maximum absorption energies for model compounds used to fit S XANES data. 


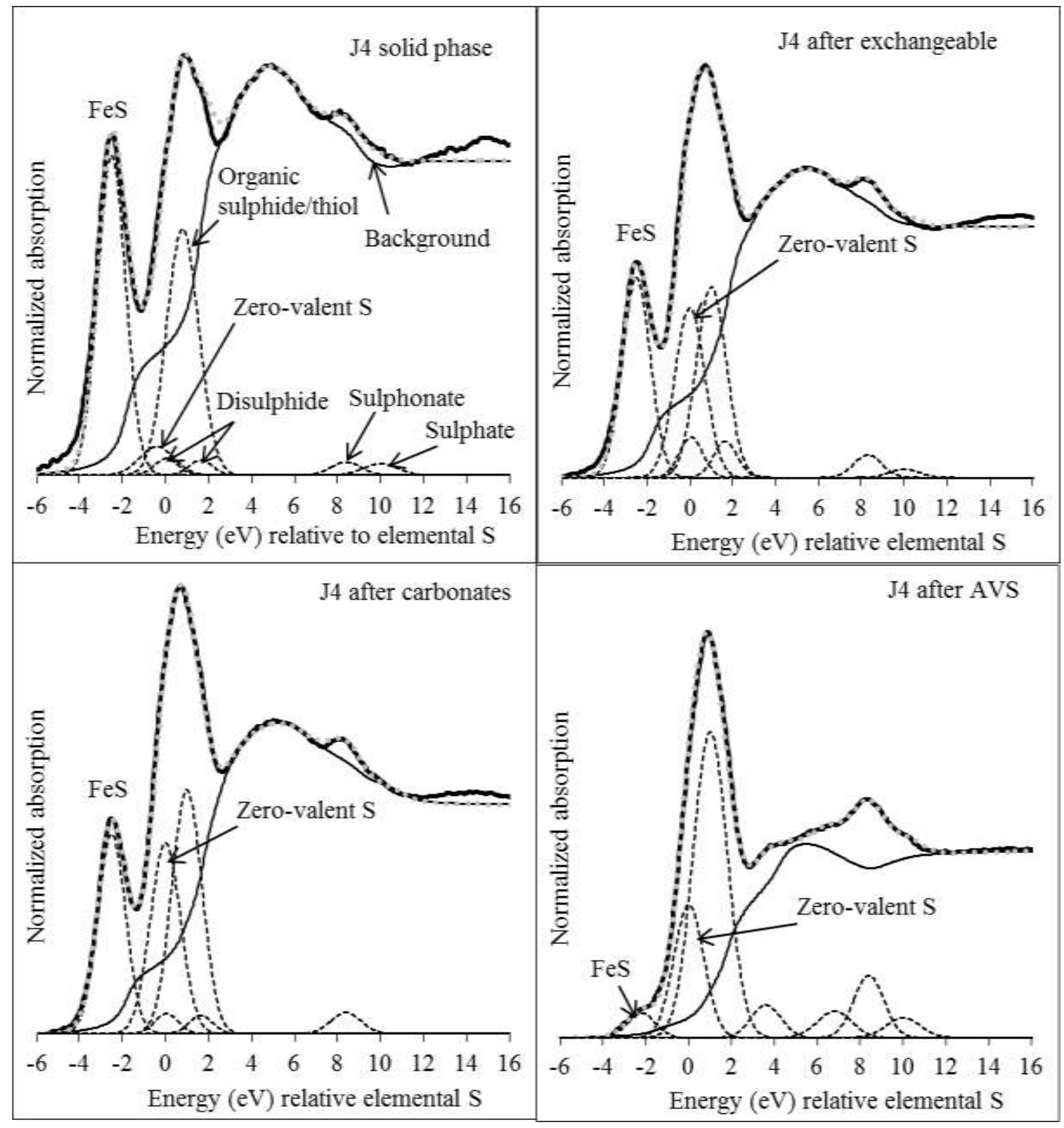

Fig. S1. Normalized S XANES spectra of the original solid sludge from the J4 reactor and solid residues after each step of sequential and AVS extraction (thick, solid line). Gaussian distribution functions, each representing a model compound, are shown by dashed lines. Overall data fits are represented by grey dotted line and the thin, solid line represents the background. 
Table S1. Peak maximum energies for model compounds (and their corresponding Gaussian functions) used to fit experimental S XANES data. The energy was calibrated against the maximum of the $\mathrm{Na}_{2} \mathrm{~S}_{2} \mathrm{O}_{3}$ first peak at $2472.0 \mathrm{eV}$. During fitting the standard deviation of Gaussian functions were set to $0.55 \mathrm{eV}$ for the cystine double peak and was constrained between 0.65 and $0.75 \mathrm{eV}$ for the rest of the model compounds. Because of peak broadening caused by possible self-absorption effects and the proximity of $\mathrm{FeS}_{2}$ and elemental S peaks, the sum of these two compounds are reported as zero-valent $\mathrm{S}$.

\begin{tabular}{|l|l|}
\hline Model compound & $\begin{array}{l}\text { Peak maximum } \\
\text { energy }(\mathrm{eV})\end{array}$ \\
\hline FeS & 2470.2 \\
\hline FeS 2 & 2472.1 \\
\hline Elemental S & 2472.7 \\
\hline DL-cystine & 2472.65 \\
(two peaks) & 2474.35 \\
\hline L-cysteine + DL- & $2473.5-2473.7$ \\
methionine & \\
\hline Sulphoxide & 2476.2 \\
\hline Sulphone & 2479.7 \\
\hline Sulphonate & $2481.0-2481.2$ \\
\hline Sulphate & 2482.7 \\
\hline
\end{tabular}

